\section{Determination of Glycaemic Responses of Low Fat Milk Incorporated with Whey Proteins and Oats Powder}

\section{Abstract}

Objective: Investigation of glycaemic responses of low fat milk, enriched with whey proteins.

Design: Randomized crossover study.

Participants: Healthy volunteers $(n=11)$ including both sexes (6 males and 5 females), aged between 20 and 30 years and with a body mass index of 18.5-23.5.

Main outcome measures: Blood glucose concentrations at fasting and 30, 45, $60,90,120$ min were measured following ingestion of; skimmed milk powder, incorporated with extra whey proteins and oats flour (4:1 ratio), containing $50 \mathrm{~g}$ of available carbohydrates. Glycaemic Index values were expressed as the average value of 11 subjects.

Results: GI for the prepared formulation was $12 \pm 2$ and the average peak reduction of compared to the standard (Glucose) was $37.7 \%$. Proximate analysis of the product indicated a higher total protein content $(36.08 \pm 2.5 \%)$ compared to fresh milk powder $(21.9 \pm 2.7 \%)$ and very low fat content $(4.34 \pm 0.5 \%)$ compared to fresh milk powder $(29.3 \pm 2.1 \%)$.

Conclusions: Incorporation of whey powder have significantly reduced the Glycaemic index of milk $(p<0.05)$. Although digestible carbohydrate content was increased by addition of oats and also being lower in fat; low GI milk powder formulations can be developed by incorporating whey proteins and cereal grains like oats.

Keywords: Glycaemic index; Low fat milk; Whey proteins; Oats

Received: July 21, 2018; Accepted: August 03, 2018; Published: August 10, 2018

\section{Introduction}

In the current scenario, about $17 \%$ individuals in the world population are assumed to be suffering from diabetes and other related non-communicable diseases, due of their improper food habits [1]. Diabetes is a non-communicable disease which is resulted by continued increase of the blood glucose levels rapidly and habitually [2]. The concepts of Glycemic Index and glycemic load are used widely to identify impacts by food sources on blood glucose rise.

There are several factors affecting the GI of food. Recent studies indicate that certain milk proteins have insulin tropic properties and may substantially increase post prandial levels of insulin [3]. According to the Ercan's research, he observed that a decrease
Manokaran $\mathrm{S}^{1}$, Jayasinghe $\mathrm{MA}^{1 *}$, Senadheera $\mathrm{AS}^{2}$, Gunathilaka SS ${ }^{3}$, Kalina S1, Chandrajith VG' and Ranaweera KDS ${ }^{1}$

1 Department of Food Science \& Technology, Faculty of Applied Sciences, University of Sri Jayewardenepura, Sri Lanka

2 Department of Biochemistry, Faculty of Medicine and Allied Sciences, Rajarata University of Sri Lanka, Sri Lanka

3 Department of Microbiology, Faculty of Medicine and Allied Sciences, Rajarata University of Sri Lanka, Sri Lanka

*Corresponding author:

Madhura A. Jayasinghe

”madhura@sci.sjp.ac.lk

Department of Food Science \& Technology, Faculty of Applied Sciences, University of Sri Jayewardenepura, Sri Lanka.

Tel: +94716255690

Citation: Manokaran S, Jayasinghe MA, Senadheera AS, Gunathilaka SS, Kalina S, et al. (2018) Determination of Glycaemic Responses of Low Fat Milk Incorporated with Whey Proteins and Oats Powder. J Clin Nutr Diet Vol.4 No.2:8

of the glucose response when a reasonable amount of fat was ingested together with carbohydrates [4].

Though several people are avoiding the dairy and dairy products because they believe it increase the obesity, osteoarthritis and CVD, according to the Serge Roz Enberg et al. [5], dairy products do not increase the risk of cardiovascular disease, particularly if low fat.

This study was designed focusing on the glycemic responses in milk powder; with reduced fat and increased whey proteins. Many high protein dairy based powder formulations available in 
the market are also rich in other calorie contributors, namely fats and carbohydrates. Although these milk powder products provide high calories and proteins, their higher impact to elevate blood glucose levels after consumption, may induce the risk of getting pre-diabetes conditions when regularly consumed. Further, the high fat content may elevate total triglycerides and LDL in blood as well. Hence, cow milk was formulated and standardized to reduce its fat and, not all reduced fat has contributed in relative increase of carbohydrates in milk, but more milk whey proteins were incorporated to the final formulation. So, the final milk product is a low fat-high protein diet.

Many Asians including Sri Lankans incorporate sugar (sucrose) when consuming milk powder as tea or as whole milk. Hence, it is important to have an initial low Glycemic Index in the formulated milk powder, which will not greatly increase the glycemic responses after incorporation of sugar to it.

Both proteins and fats in food are known to reduce the blood glucose elevations [6], but it was unknown which may have higher impact to reduce $\mathrm{Gl}$ in dairy sources. Therefore, this study will be a determining factor to understand the realistic and relative impact on glycemic responses by milk whey proteins and milk fat altogether.

\section{Materials and Methods}

\section{Materials}

Fat was reduced (5.31\%) in cow milk (15 L) and was spray dried to reduce moisture up to $3.5 \%$. Oats powder and whey protein powder were obtained from reputed commercial brands and ground to make a fine powder (particle size 0.05-0.01 mm). For $100 \mathrm{~g}$ of milk powder, $20 \mathrm{~g}$ of whey and $10 \mathrm{~g}$ of oats powder were incorporated.

Preparation of breakfast meals: Skimmed milk powder was mixed with powdered oats and whey. The ratios of food ingredients for each food were selected by considering the palatability test decided via a panel (non-trained).

Analysis of proximate composition: Proximate compositions of the powder mixture was determined. The moisture and ash contents were measured by AOAC official methods $[7,8]$. The digestible carbohydrate content, fat and soluble \& insoluble dietary fibre was determined with Holm's method [9], Croon and Guchs [10] and by the method of Asp [11] respectively. The crude protein was by Kjeldahl method using Copper/ Selenium catalysts [12].

Ethical clearance: Ethical clearance (No.77/17) was obtained from the Ethical Review Committee, Faculty of Medical Sciences, University of Sri Jayewardenepura, Sri Lanka. Informed written consent from all participating subjects was obtained prior to the study.

Determination of glycaemic indices: Determination of the GI was carried out as a randomized crossover study, reviewed by
Brouns et al. in 2005 [13]. Healthy volunteers $(n=11)$ including both sexes ( 6 males and 5 females), aged 20 - 30 years and with a body mass index of 18.5-23.5 were selected. The subjects were asked to refrain from smoking, taking alcohol and to restrict vigorous physical activities the day before.

Glucose was used as the standard food $(G \mid=100)$. The test food (within 2 hours following preparation) and the standard food were served to the same individual on separate occasions randomly. Following an overnight fast of $8-12$ hours, a finger prick capillary blood sample was obtained from the subject. The subject was served with standard or test food containing $50 \mathrm{~g}$ of digestible carbohydrate portions to be consumed within 10 minutes with $250 \mathrm{ml}$ drinking water. Capillary blood samples were collected at 30,45, 60, 90 and 120 min following the first bite of the meal. Serum glucose concentrations were determined with a Glucose-Oxidase kit (BIOLABOSATM; Biolabosa, France). The GI was calculated using the mean of the individual incremental area under the curve of the test food and of the standard food [13]. The glycaemic load (GL) value of the test food was calculated. (GL $=\mathrm{GI}$ *digestible starch per serving $(\mathrm{g})) / 100$ ).

Statistical analysis: Proximate composition values were expressed as the mean \pm standard deviation. GI values are expressed as the mean with SEM. The means of the GI values of test food were compared with typical cow milk, using a paired Student's t-test using Microsoft Excel 2013 at 95\% confidence level.

\section{Results}

Proximate compositions of fresh cow milk powder and the formulated new powder sample are stated in Figure 1. Significant differences were observed $(p<0.05)$ in all three macronutrient contents (fat, protein, digestible carbohydrates) between the two samples. Crude fibre contents in both samples were not measurable. The remainders were considered to be mineral ash.

GI for the prepared formulation was $12 \pm 2$ (Low GI) and that is significantly $(p<0.05)$ lower compared to the stated $\mathrm{Gl}$ of fresh milk, that is 36 as was found by David et al. [14]. A lowering of GI about three times in the new powder formulation was achieved due to incorporation of whey and oats powder to replace great amount of milk fat.

The average maximum peak value for glucose is 162.7 , and the average peak value for the newly formulated powder was greatly reduced up to 101.3 (Table 1 ). Hence the peak reduction is by $37.73 \%$ (Table 2 ).

The glycaemic response curve of the prepared powder formulation (Figure 2) clearly indicated a lower peak value compared to the standard (Glucose). The peaking time was observed earlier by 15 minutes compared to glucose (Figure 2).

According to the Glycaemic Load scale GL values $\geq 20$ are considered as high, between 11 to 19 as intermediate and $\mathrm{GL} \leq$ 10 as low. The calculated GL value for the formulated powder sample was 2.3 (Table 2 ); that indicates of a very low GL value. 


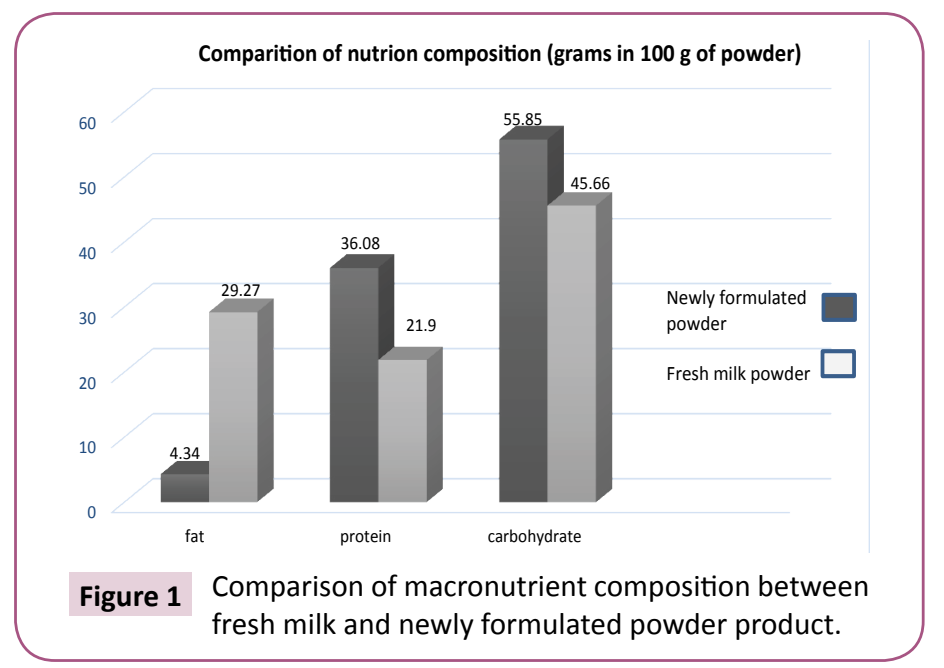

Table 1: Average blood glucose values with time.

\begin{tabular}{|c|c|c|c|c|c|c|c|c|}
\hline Food & $\mathbf{0} \mathrm{min}$ & $\mathbf{1 5} \mathrm{min}$ & $\mathbf{3 0} \mathrm{min}$ & $\mathbf{4 5} \mathrm{min}$ & $\mathbf{6 0} \mathrm{min}$ & $\mathbf{9 0} \mathrm{min}$ & $\mathbf{1 2 0} \mathrm{min}$ \\
$\begin{array}{c}\text { Standard } \\
\text { (Glucose) }\end{array}$ & 93.4 & 128.7 & 151.9 & 162.7 & 137.2 & 120.5 & 96.5 \\
\hline $\begin{array}{c}\text { Formulated } \\
\text { sample }\end{array}$ & 92.4 & 99 & 101.3 & 95.8 & 95.3 & 97.4 & 93.1 \\
\hline
\end{tabular}

Table 2: Detailed glycemic response results in newly formulated powder.

\begin{tabular}{|c|c|}
\hline Mean GI & $12 \pm 2$ \\
\hline Standard error mean & 1.7 \\
\hline Portion size & $350 \mathrm{~mL}$ \\
\hline Peaking time & $30 \mathrm{~min}$. \\
\hline Peak reduction & $61.4 \mathrm{mg} / \mathrm{dL}$ \\
\hline \% Peak Reduction (compared to Glucose) & 37.73 \\
\hline GI reduction (Compared to fresh milk) & 66.7 \\
\hline Glycaemic Load & 2.3 \\
\hline
\end{tabular}

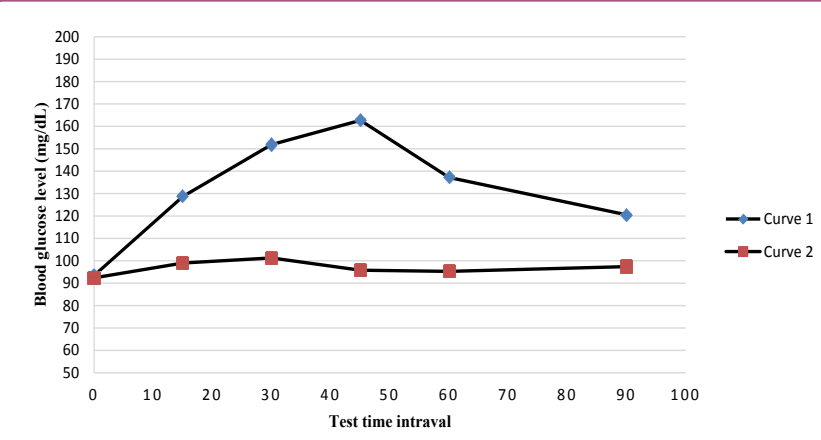

*Curve 1: Glucose (standard) Curve 2: Newly formulated powder

Figure 2 Blood glucose response curves (Glucose vs. formulated sample).

\section{Discussion}

Since there was a significant reduction in GI compared to fresh milk in the newly formulated powder; it can be assumed that whey proteins has a great impact in reducing glycemic responses. The digestible carbohydrate content was higher due to incorporation of oats powder. The fat; which is a known factor for reducing $\mathrm{Gl}$, was lower in the new formulation compared to fresh milk. The results of proximate analysis did not reveal of a considerable inclusion of dietary fibre by oats powder to the new formulation as well. Hence, the addition of whey proteins can be considered as the crucial factor affecting the significant reduction observed in GI.

Cow milk contains, many essential nutrients which helps to maintain the healthy human life style. According to some scientists, there is no evidence to achieve essential nutrients requirement by a dairy free diet [5]. The problem is that; may Asians including Sri Lankans carry the habit of incorporating sugar when drinking milk. Hence, it is of utmost importance to decrease the initial GI of milk as low as possible.

It was unknown that how the reduction of fat and increment of whey proteins together impact on the glycemic impact on milk; especially when the digestible carbohydrate content too is increased by addition of cereals like oats. Both the increment of digestible carbohydrate content by addition of cereal powder, and also reduction of fat can increase the GI, but this study reveals that; incorporation of a considerable amount of whey proteins can overcome both those impacts.

Glycaemic load allows comparisons of the likely glycaemic effect of realistic portions of different foods, calculated as the amount of carbohydrate in one serving times the GI of the food. Majority of the volunteers mentioned that the portion size $(89.5 \mathrm{~g}$ of powder in total of $350 \mathrm{~mL}$ volume) of newly formulated powder product as 'larger'. Therefore, the GL value for the considered powder formulation may be lower, when considering the actual portion size of a daily consumption.

This study reveals of a very negative impact on blood glucose elevations by whey proteins which exceeds such an impact by the milk fat content. Hence, these findings may be of importance for dairy powder producers in future.

\section{Conclusion}

Whey protein has a great impact on reducing glycemic responses of milk. That can overtake the impact to increase the $\mathrm{GI}$ in milk by reduction of fat and also a little increase of digestible carbohydrates by addition of cereal powders such as oats. Hence, this information can be used by industrial producers in formulating low fat-high protein milk powder products.

\section{Acknowledgement}

We are grateful to Prof. Sampath Amarathunga, the vice chancellor of University of Sri Jayewardenepura - Sri Lanka and Prof. Sudantha Liyanage, the Dean of the faculty of Applied Sciences. 


\section{References}

1 American Diabetes Association (2013) Standards of medical care in diabetes.

2 Bell KJ, Smart CE, Steil GM, Brand-Miller JC, King B, et al. (2015) Impact of fat, protein, and glycemic index on postprandial glucose control in type 1 diabetes: implications for intensive diabetes management in the continuous glucose monitoring era. Diabetes Care 38: 1008-1015.

3 Nilsson M, Stenberg M, Frid AH, Holst JJ, Bjorck IM (2004) Glycemia and insulinemia in healthy subjects after lactose-equivalent meals of milk and other food proteins: the role of plasma amino acids and incretins. Am J Clin Nutr 80: 1253-1246.

4 Ercan N, Gannon MC, Nuttall FQ (1994) Effect of added fat on the plasma glucose and insulin response to ingested potato given in various combinations as two meals in normal individuals. Diabetes Care 17: 453-459.

5 Rozenberg S, Body JJ, Bruyère O, Bergmann P, Brandi ML, et al. (2016) Effects of dairy products consumption on health: benefits and beliefsa commentary from the Belgian Bone Club and the European Society for Clinical and Economic Aspects of Osteoporosis, Osteoarthritis and Musculoskeletal Diseases. Calcif Tissue Int 98: 1-17.

6 Moghaddam E, Vogt JA, Wolever TM (2006) The effects of fat and protein on glycemic responses in nondiabetic humans vary with waist circumference, fasting plasma insulin, and dietary fiber intake. J Nutr 136: 2506-2511.

7 Association of Official Analytical Chemists (1984) Official Methods of Analysis of the AOAC 1984. $14^{\text {th }}$ edition AOAC: Washington DC, 7.009 .

8 Association of Official Analytical Chemists (1984) Official Methods of Analysis of the AOAC $14^{\text {th }}$ edition. AOAC: Washington DC, 14.004 .

9 Holm J, Drews A, Asp NG (1986) A rapid method for the analysis of starch. Starch/Starke 38: 226-224.

10 Croon LB, Guch G (1980) Crude fat analysis of different flours and flour products. Var Foda 32: 427-425.

11 Asp NG, Johansson CG, Hallmer H, Siljestrom M, et al. (1983) Rapid enzymatic assay of insoluble and soluble dietary fiber. J Agr Food Chem 31: 478-476.

12 Association of Official Analytical Chemists (1987) Official Methods of Analysis of the AOAC. Washington DC 7.033.

13 Brouns F, Bjorck I, Frayn KN, Gibbs AL, Lang V, et al. (2005) Glycaemic index methodology. Nutrition Research Reviews 18: 171-145.

14 Jenkins DJ, Wolever TM, Taylor RH, Barker H, Fielden H, et al. (1981) Glycemic index of foods: a physiological basis for carbohydrate exchange. Am J Clin Nutr 34: 362-366. 